\title{
Single Prolonged Stress induces ATF6 alpha-dependent Endoplasmic reticulum stress and the apoptotic process in medial Frontal Cortex neurons
}

\author{
Bo Yu' ${ }^{1}$, Lili Wen², Bing Xiao ${ }^{2}$, Fang $\mathrm{Han}^{2}$ and Yuxiu Shi ${ }^{2,3^{*}}$
}

\begin{abstract}
Background: In our previous researches, we have found that apoptosis was induced in the medial prefrontal cortex (mPFC) of post-traumatic stress disorder (PTSD) rats. Endoplasmic reticulum (ER) stress-induced apoptosis has been implicated in the development of several disorder diseases. The aim of this study was to investigate whether endoplasmic reticulum-related pathway is involved in single-prolonged stress (SPS) induced apoptosis in the mPFC of PTSD rats by examining the expression levels of ATF6 alpha (ATF6a), two important downstream molecular chaperones of ATF6a in the ER stress: Glucose-regulated protein (GRP) 78 and ERP57, and apoptotic factors caspase 12, caspase 9, and caspase 3.
\end{abstract}

Results: Our results of Morris Water Maze (MWM) test showed that after SPS exposure, a striking increase of the escape latency was observed in SPS rats at day 1 through day 6, and SPS rats had much less time spent in target quadrant compared to control rats $(P<0.01)$. And From immunofluorescence assays, we found that there was a gradual increase on the protein expression of ATF6a in response to SPS, which indicated ATF6a was activated by SPS. And additionally, immunohistochemistry assays, western blotting and reverse transcription-polymerase chain reaction (RT-PCR) showed that the immunoreactivity, protein and mRNA expression of GRP78 and ERP57 increased on 1, 4 days, and peaked on 7 days after SPS exposure, which revealed that SPS triggered inductions of GRP78 and ERP57 in the MPFC neurons. Moreover, RT-PCR assays demonstrated that there were up-regulations in the transcripts levels of caspase 12, caspase 9, and caspase 3 in response to SPS, which were according with the proteins changes of these apoptotic factors and indicated that ER stress and the activation of caspases contributed to SPS.

Conclusion: Current data in this study highlight that SPS induced ATF6a-dependent Endoplasmic reticulum stress and ER-related apoptosis in the MPFC neurons, which indicated that the endoplasmic reticulum pathway may be involved in PTSD-induced apoptosis.

Keywords: Single-prolonged stress, Post-traumatic stress disorder, Medial prefrontal cortex, Activating transcription factor 6a, Glucose-regulated protein, ERP57, Caspase, Rat

\footnotetext{
* Correspondence: shiyuxiu@163.com

${ }^{2}$ Department of Neurosurgery, Shengjing Hospital, China Medical University, Shenyang, China

${ }^{3}$ Institute of pathology and pathophysiology, Department of Histology and Embryology, Basic Medical Sciences College, China Medical University, 92 North 2nd Road, Shenyang 110001, Liaoning Province, P.R. China

Full list of author information is available at the end of the article
} 


\section{Background}

PTSD is an unique psychiatric disorder in that it is the result of a traumatic life event, and characterized by four clusters of symptoms: re-experiencing of fear memories, avoidance of trauma reminders, hyperarousal symptoms and negative alterations in cognition and mood [1-3], which may appear after a few days or months, even last several years $[4,5]$. Over the past several years, neuroimaging studies of PTSD have reported less activation or even deactivation in the medial prefrontal cortex (mPFC) regions during traumatic script-driven imagery in PTSD [6-8], and emerging studies showed that PTSD patients had a smaller mPFC [9]. And all these reports have been implicated that less activation of MPFC is associated with the pathogenesis of PTSD, and has played a key role in this disorder.

In the past several years, our research team have made great efforts on the dysfunction of the MPFC in the study of PTSD, and found there were apoptosis morphological changes by transmission electron microscopy (TEM) in the mPFC neurons of single prolonged stress (SPS)-model rats [10], which is a reliable animal model of PTSD, exhibiting behavioral abnormalities of PTSD and inducing enhanced inhibition of the hypothalamic-pituitary-adrenal (HPA) axis [11], as is a putative neuroendocrinological hallmark of PTSD [12]. However, the exact apoptosis mechanisms in the $\mathrm{mPFC}$ neurons remain poorly understood and require a deeper understanding of the cellular and molecular responses to SPS in order to reveal the pathophysiology changes of PTSD.

Apoptosis is also called programmed cell death. In recent years, endoplasmic reticulum stress (ERS) pathway is discovered as another important pathway of apoptosis [13]. ER is an essential intracellular organelle which is responsible for the synthesis and maturation of cell surface and secretion proteins, and maintenance of $\mathrm{Ca}^{2+}$ homeostasis. Disruption of these physiological functions leads to accumulation of unfolded proteins and induces ER stress. At the beginning, ER stress triggers the adaptative pathway, unfolding protein response (UPR) [14,15], which is essentially carried out by utilizing three types of ER stress sensor proteins, PERK (double stranded RNAactivated protein kinase-like ER kinase) [16], IRE1 $\alpha$ (inositol requiring kinase 1 $\alpha$ ) [17], and ATF6 $\alpha$ (activating transcription factor $6 \alpha$ ) [18], and results in the upregulation of ER-derived chaperones and protein-folding enzymes leading the misfolded proteins undergoing the process of degeneration, such as an increase of glucose-related protein (GRP) family, such as GRP78/Bip, and the protein disulfide isomerase (PDI) family, such as ERP57/GRP58 [19,20].

Under normal conditions, ER chaperone GRP78 directly interacts with all three ER stress sensors, PERK, ATF6 and IRE1, and maintains them in inactive forms in non-stressed cells [21], and ERP57 plays a key role as folding catalysts [22]. And when ER stress occurs, GRP78 is released and allows the activation and transduction of the unfolded protein signals across the ER membrane to the cytosol and the nucleus [23], and ERP57 acts as a thiol oxidoreductase to catalyze the disulfide bond formations of the loaded glycoproteins [22]. And among this process, the glycosylation and disulphide bond status of the luminal domain of ATF6 can be utilized as novel sensing mechanisms for the activation of the UPR, and the cleavage to generate the active nuclear form of ATF6, and transported from ER to Golgi and then to the nucleus, to up-regulate the expression of GRP78 and ERP57 and reduce the unfolded protein load $[24,25]$.

However, when ER homeostasis cannot be restored, the pro-apoptotic process is irreversibly induced [26], executed by ER resident Caspase 12 [27], which is a key signal involved in ER stress-induced apoptosis, localized on the cytoplasmic side of the ER, and Nakagawa et al. have been found that has been cells from Caspase 12 deficient mice are resistant to apoptosis triggered by the known ER stress agents [28]. Caspase 12 is specifically activated when ER stress is induced, and the activated Caspase 12 will enter cytoplasm from ER, gradually activate Caspase 9 and Caspase 3, and eventually induce ER stress-induced apoptosis. As during ER stress, activation of ATF6 is known to specifically up regulate chaperones, PDIs, as well as Caspase 12, and consequently lead to apoptosis [29], thus, the aim of this study was to investigate whether endoplasmic reticulum -related pathway is involved in SPS induces apoptosis in the mPFC of PTSD rats by examining the expression levels of ATF6 alpha (ATF6 $\alpha$ ), two important downstream molecular chaperone: GRP78 and ERP57, and apoptotic factors Caspase 12, Caspase 9, and Caspase 3.

\section{Methods}

\section{Ethics statement}

The study was approved by the ethics committee of China Medical University. All Wistar rats were maintained under clean grade. Housing and experimental protocols were in accordance with the Chinese Regulations for the Administration of Affairs Concerning Experimental Animals. All efforts were made to minimize the suffering of experiment animals during the procedures.

\section{Experimental animals}

A total of 80 male Wistar rats, weighing 150-180 g, about 6 - 7 weeks old, were purchased from the Department of Laboratory Animals, China Medical University, and were pair-housed in a room with temperature of $22 \pm 2^{\circ} \mathrm{C}$ and humidity of $55 \pm 5 \%$. All rats were housed under a reversed $12 \mathrm{~h}: 12 \mathrm{~h}$ light/dark cycle (lights off at 10.00 a.m) and given standard food pellets and water. 


\section{Groups and establishment of SPS model}

After lab adaptation and handling, the rats were randomly assigned to one of four groups of twenty. One group served as a normal control (control), while others were SPS groups. The control group remained in their home cages with no handling until them were killed for test, and at the same time other rats were sacrificed at 1, 4 and 7 days after SPS, respectively called SPS1d group, SPS4d group and SPS7d group. The SPS model was created as described previously [30], which was described in "Advances in Basic and Clinical Research" international conference launched by Japanese Ministry of Education in 2005. Briefly, rats were restrained for $2 \mathrm{~h}$ and immediately forced to swim for $20 \mathrm{~min}$ in water $\left(24^{\circ} \mathrm{C}\right)$. After a 15 -min rest, they were anaesthetized by ether and then laid in their cages without disturbance until the experimental manipulations.

\section{Behavioral testing- Morris Water Maze (MWM) test}

To measure learning and spatial memory performance, rats were tested in the Morris water maze (MWM) which based on the classic Morris protocol. Keep the water temperature $(25 \pm 1)^{\circ} \mathrm{C}$, and surrounding environment was quiet and with constant light source. A 6-day testing study was performed as previously described in detail spatial reference and working memory deficits assessed in the water maze fixation and sections making [31]. Briefly, rats were initially brought into a quadrant (not containing the platform), facing the wall of the pool, to find the submerged platform within 120s. They were then allowed to stay on the platform for 20s. For learning performance, rats had four 120 s learning trials daily each starting one of four quadrants in a random manner, with a 20 s interval between trials. The escape latency to find the platform, calculated by averaging four trial values, was used to represent learning performance. Each rat was tested 6 consecutive days for learning performance. Spatial memory was evaluated at day 7 using the probe test, i.e., the platform was removed and animals were placed at a novel position. Average time spent in the target quadrant (platform removed) was calculated as an index for spatial memory.

\section{Brain tissue preparation and immunoflourescence assay for ATF6a}

Five rats of each group were deep anesthetized with Nembutal (30 mg/kg, i.p.), and then infused with 200$300 \mathrm{ml}$ of pre-cold saline through the ascending aorta, followed by $300 \mathrm{ml}$ of $4 \%$ pre-cold paraformaldehyde (PFA) in $0.01 \mathrm{M}$ PBS. The whole brain was rapidly removed and dissected on ice, followed by 6-10 h of post-fixation in $4 \% \mathrm{PFA}$ at $4^{\circ} \mathrm{C}$. Then the brains were embedded in paraffin. Samples were cut into 7 um thick and mounted on glass slides until to the morphological studies.
Dewaxed sections were incubated with mouse polyclonal antibody against ATF6 $\alpha$ (Santa Cruz, USA, 1:150) overnight at $4^{\circ} \mathrm{C}$. After three times washing, the sections were incubated with CY3 anti-mouse IgG (Company of Zhongshan Goldenbridge, Beijing, China, 1:200) for $0.5 \mathrm{~h}$ at room temperature. After being washed in PBS and mounted. Confocal laser scanning microscope was applied for localization observation, and five slides were randomly selected from each group, each slide was randomly selected five visual fields in $\operatorname{mPFC}(\times 400)$, and eventually we recorded the optical density (OD) of positive cells in each field to evaluate the average of OD, andanalyzed using the MetaMorph/DPIO/BX41 morphology image analysis system.

\section{Immunohistochemical analysis for GRP78 and ERP57}

Dewaxed sections were incubated with $0.3 \%$ hydrogen peroxide for $10 \mathrm{~min}$, and later boiled in $10 \mathrm{mM}$ citrate buffer $\left(\mathrm{pH} \mathrm{6.0)}\right.$ in a water bath at $99^{\circ} \mathrm{C}$ for $5 \mathrm{~min}$. Tissue sections were then incubated with the primary antibodies overnight at $48 \mathrm{C}$. The antibodies were used at dilutions of 1:500 for GRP78 (Santa Cruz, USA) and ERP57 (Santa Cruz, USA). Then the sections were incubated with twostep IHC detection reagent (PV6001 and PV6002, Company of Zhongshan Goldenbridge, Beijing, China) at $37^{\circ} \mathrm{C}$ for $30 \mathrm{~min}$. A brown color appeared in the slices after 3, 3 '-diaminobenzidine colorization. Slices were then dehydrated and mounted with neutral gum. To assess nonspecific staining, a few sections in every experiment were incubated in PBS without primary antibody. Five slides were randomly selected from each group. Each slide was randomly selected five visual fields in mPFC $(\times 400)$. We recorded the optical density (OD) of positive cells in each field to evaluate the average of OD, and analyzed using the MetaMorph/DPIO/BX41 morphology image analysis system.

\section{Western blotting to detect the protein expression of GRP78, ERP57}

Five rats of each group were decapitated, and the whole brains were removed and immediately placed in an icecold dish. Then the mPFC was dissected according to the atlas [32] by use of a stereomicroscope and was quickly frozen in liquid nitrogen and stored $-80^{\circ} \mathrm{C}$. The mPFC was homogenized with a sample buffer containing $200 \mathrm{mM}$ TBS, pH 7.5, 4\% SDS, 20\% glycerol, 10\% 2mercaptoethanol and denatured by boiling for $5 \mathrm{~min}$. The protein fraction $(50 \mu \mathrm{g} /$ lane $)$ prepared from each sample was separated by $8 \%(\mathrm{w} / \mathrm{v})$ gradient sodium dodecyl sulfate(SDS)-polyacrylamide gel electrophoresis (PAGE) and electroblotted to a PVDF membrane (Millipore, Bedford, MA, USA) from the gel by a semi-dry blotting apparatus (Bio-Rad Laboratories, Inc., Hercules, CA, USA). After blocked with $5 \%$ dried skim milk, the membrane was 
incubated with I antibody (anti-GRP78, Santa Cruz, USA, 1:1000; anti-ERP57, Santa Cruz, USA, 1:1000; antiGADPH, Zhongshan Glodenbridge Biotechnology, China; $1: 1000$ ) for $24 \mathrm{~h}$ at $4^{\circ} \mathrm{C}$ and II antibody (Boster Biological Technology Ltd., 1:3000) for $2 \mathrm{~h}$ at room temperature. Blots were subjected to autoradiography (ECL reagents, Amersham Pharmacia Biotech, Buckinghamshire, UK). The optical density (OD) was analyzed on the Gel Image Analysis System. The expression of GRP78 and ERP57 were determined by calculating the OD ratio of GRP78/ GADPH and ERP57/GADPH.

\section{Terminal deoxynucleotidyl transferase dUTP Nick-end labeling (TUNEL) staining}

TUNEL staining was also carried out in order to further verify the mPFC apoptosis according to the kit instruction (KeyGEN BioTECH). Five slides were randomly selected from the control group and the SPS-7d group, and in each slide, five visual fields $(\times 400)$ in the mPFC were randomly selected. The number of TUNELpositive cells was counted and The TUNEL-positive cells rate was calculated to equal (the number of TUNEL positive cells/total cells) $\times 100 \%$.

\section{Total RNA extraction and RT-PCR}

Tissues from three rats of each group were obtained as above and was quickly frozen in liquid nitrogen and stored $-80^{\circ} \mathrm{C}$. Total RNA was extracted from the frozen mPFC using Trizol (Invitrogen, USA) Kit according to the manufacturer's instructions. $1 \mu \mathrm{g}$ of total RNA was reverse transcribed into cDNA, and the cDNA concentration and purity were determined by measuring $\mathrm{OD}_{260}$ and $\mathrm{OD}_{260 / 280}$ ratio. Then cDNA was amplified using an RNA PCR Kit(AM Ver.3.0, TaKaRa bio, Otsu, Japan). All primers were designed using DNA star Primer Select program (Lasergene, Madison, WI, USA) and synthesized by Shanghai Sangong (Shanghai, China) according to the serial number from Genbank, and the sequence of each gene was shown in Table 1. The amplification profile of GRP78 and caspase 9 included: i) denaturation at $95^{\circ} \mathrm{C}$ for $4 \mathrm{~min}$, ii) 30 additional cycles at $94^{\circ} \mathrm{C}$ for $45 \mathrm{sec}$ and then $45 \mathrm{sec}$ at $55^{\circ} \mathrm{C}, 72^{\circ} \mathrm{C}$ for $60 \mathrm{sec}$, and iii)extension at $72^{\circ} \mathrm{C}$ for $5 \mathrm{~min}$. The amplification profile of ERP57 included: i) denatureion at $94^{\circ} \mathrm{C}$ for $4 \mathrm{~min}$, ii) 30 additional cycles at $94^{\circ} \mathrm{C}$ for $45 \mathrm{sec}$ and then $45 \mathrm{sec}$ at $55^{\circ} \mathrm{C}, 72^{\circ} \mathrm{C}$ for $60 \mathrm{sec}$, and iii) extension at $72^{\circ} \mathrm{C}$ for $5 \mathrm{~min}$. The amplification profile of caspase 12 , and caspase 3 included: i) denatureion at $94^{\circ} \mathrm{C}$ for $4 \mathrm{~min}$, ii) 35 additional cycles at $94^{\circ} \mathrm{C}$ for $45 \mathrm{sec}$ and then $45 \mathrm{sec}$ at $55^{\circ} \mathrm{C}, 72^{\circ} \mathrm{C}$ for $60 \mathrm{sec}$, and iii) extension at $72^{\circ} \mathrm{C}$ for 5 min. GAPDH mRNA used as an internal control was co-amplified with them. The PCR products were separated on $2.0 \%$ agarose gel by electrophoresis and the density of each band was analyzed on the Gel Image
Table 1 All primers for RT-PCR

\begin{tabular}{|c|c|c|}
\hline Name & Primer & $\begin{array}{l}\text { Product } \\
\text { size }\end{array}$ \\
\hline \multirow[t]{2}{*}{ GRP78 } & sense 5' -CCAAGAGAGGGTTCTTGAATCTCG -3' & $181 \mathrm{bp}$ \\
\hline & antisense $5^{\prime}$-ATGGGCCAGCCTGGATATACAACA -3' & \\
\hline \multirow[t]{2}{*}{ ERP57 } & sense 5' -GTGTTGGAACTGACGGACGA -3' & $114 \mathrm{bp}$ \\
\hline & antisense 5' -GGCAAGCCTCTTGCAATGTC -3' & \\
\hline \multirow[t]{2}{*}{ Caspase12 } & sense $5^{\prime}$-GCACATTCCTGGTCTITATGTCCC -3' & $242 \mathrm{bp}$ \\
\hline & antisense 5' -TTCCTCATCTGTATCAGCAGTGGC -3' & \\
\hline \multirow[t]{2}{*}{ Caspase9 } & sense $5^{\prime}$-TGGTGGTGAGCAGTTGACC -3' & $189 \mathrm{bp}$ \\
\hline & antisense 5' -CCTGGGAAGGTGGAGTAGGA -3' & \\
\hline \multirow[t]{2}{*}{ Caspase3 } & sense 5' -CGGACCTGTGGACCTGAAAA-3' & $219 \mathrm{bp}$ \\
\hline & antisense 5' -TAGTAACCGGGTGCGTAGA -3' & \\
\hline \multirow[t]{2}{*}{ GAPDH } & sense 5' -ACTTTGGCATCGTGGAAGGG-3' & 264 bp \\
\hline & antisense 5' -ACTTGGCAGGTTTCTCCAGG -3' & \\
\hline
\end{tabular}

Analysis System (Tanon 2500R, Shanghai, China). The levels of these were normalized by GAPDH.

\section{Statistical analysis}

All data were analyzed by one-way analysis of variance (ANOVA) using the Tukey's test to adjust for multiple comparisons or student's t test where appropriate using SPSS 17.0 software. Data from multiple experiments were averaged and expressed as mean values \pm SEM. A value of $\mathrm{P}<0.05$ was considered as statistically significant.

\section{Results}

\section{Prolonged escape latency was observed in SPS rats from MWM Test}

The results of MWM test are illustrated in Figure 1. Compared to control group, a striking increase of the escape latency was observed in SPS rats at day 1 through day 6 (Figure 1A). When the platform was removed from the pool at day 7 for spatial memory testing, a significant effect was observed across the two groups, the results showed that SPS rats had much less time spent in target quadrant compared to the control rats (Figure 1B), and revealed that SPS model was successfully copied, which had provided guarantee for subsequent studies.

\section{ATF6a was activated in response to SPS}

ATF6 is an ER-membrane-bound transcription factor, a typical ER stress transducer and is localized to ER membranes [33]. It is activated by ER stress by cleavage from the membrane, moved to the nucleus and activated transcription $[33,34]$. In the current study, we hypothesized that SPS would result in the activation of ATF6 $\alpha$. To address this hypothesis, the effect of SPS on the expression of ATF $6 \alpha$ was examined by immunoflourescence analysis. As shown on Figure 2A, ATF6 $\alpha$ was present in the normal control rats and showed diffused cytoplasmic 

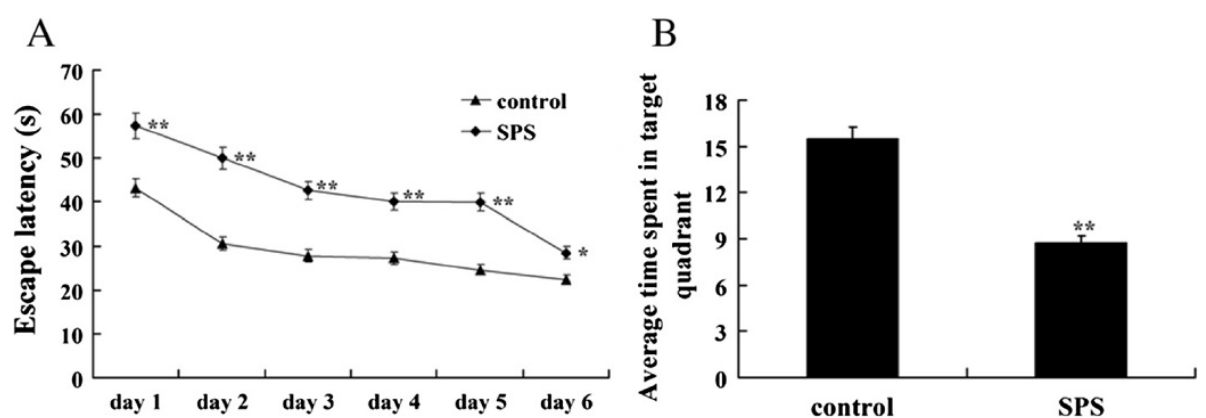

Figure 1 Results of the MWM test. (A): Escape latency of three group rats in different test days. (B): Average time spent in the target quadrants. $n=5$ for each group, and statistical analysis was carried out by Tukey test. ${ }^{* *} \mathrm{P}<0.01$ compared to control group.

localization, whereas obvious increases of ATF6 $\alpha$ were detected in response to SPS (Figure 2B-D and 2E), started at the early stage and persistently increased till 7 days. And all these results suggested that ATF6 $\alpha$ was activated in response to SPS.

Upregulation of GRP78 in the MPFC neurons after SPS exposure in immunohistochemical experiment GRP78 is a key regulator of ER stress transducer-ATF6 $\alpha$, and plays critical cytoprotective roles in neurodegenerative diseases $[35,36]$. To address the contribution of ATF6 $\alpha$ activation, GRP78 was detected with immunohistochemistry assays in the current study. As shown in Figure 3A, GRP78 (ir) was distributed mainly in the cytoplasm of the mPFC neurons in the control group. All SPS groups showed higher immunoreactivity than the control groups (shown in Figure 3B-3D and 3E), and at SPS7d after SPS, the GRP78-ir positive cells reached a peak (Figure 3D and $3 \mathrm{E}$ ), which revealing an upregulation of GRP78 in the $\mathrm{mPFC}$ neurons in response to SPS.
Increase of ERP57 in the MPFC neurons after SPS exposure in immunohistochemical assay

During ER stress, activation of ATF6 $\alpha$ is also known to specifically up regulate PDIs, such as ERP57 [29], thus we determined to detect the protein expression of ERP57 after SPS exposure by immunohistochemistry assays. As 1 day after SPS, increased expression of ERP57 was observed from Figure $4 \mathrm{~B}$ and $4 \mathrm{E}$, then gradually climbing, and peaked at 7 days after SPS (Figure 4B-4D and 4E), indicative of an increase of ERP57 in the mPFC neurons in response to SPS.

\section{SPS triggered increases in the protein levels of GRP78 and ERP57}

Western blotting was also used to detect the protein expressions of GRP78 and ERP57 in MPFC of PTSD rats. Molecular weights of GRP78, ERP57 and GADPH were $78 \mathrm{kD}, 57 \mathrm{kD}$ and $36 \mathrm{kD}$, respectively, and the clear representative bands were shown in Figure 5A. The protein expression of GRP78 and ERP57 in the SPS groups showed a marked increase compared to that of the control group,
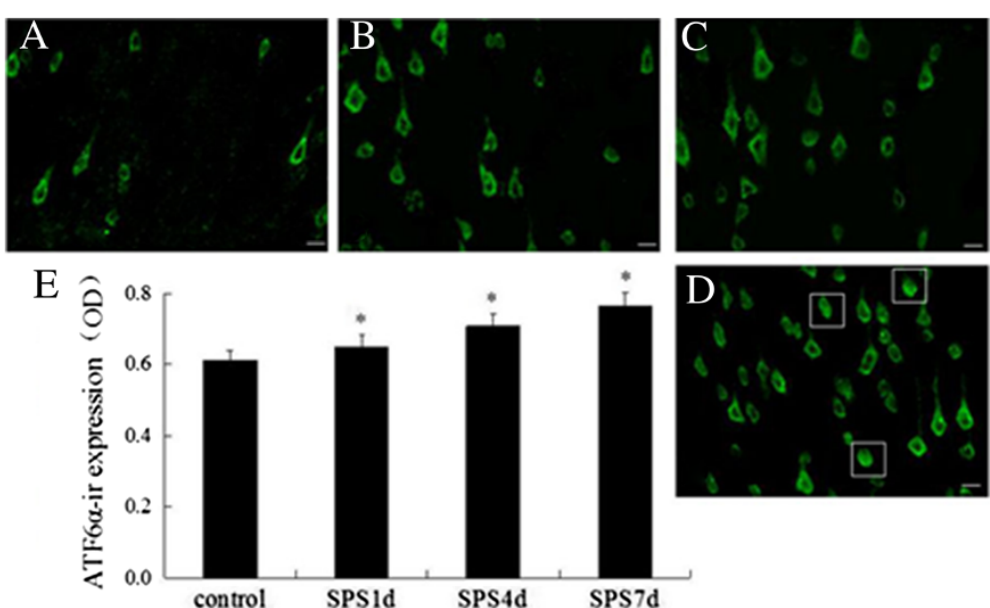

Figure $\mathbf{2}$ Immunoflourescence observation of ATF6a visualized localization. ATF6a-immunoreactivity (ir) in the mPFC of SPS rats in different groups (A-D, magnification $\times 400$ ). A: the control group; B: the SPS1d group; C: the SPS4d group; D: the SPS7d group; E: the quantity of ATF6a-ir expression (OD). $n=5$ for each group, scale bar $=30$ um, and statistical analysis was carried out by Tukey test. ${ }^{*} P<0.05$ versus control. 

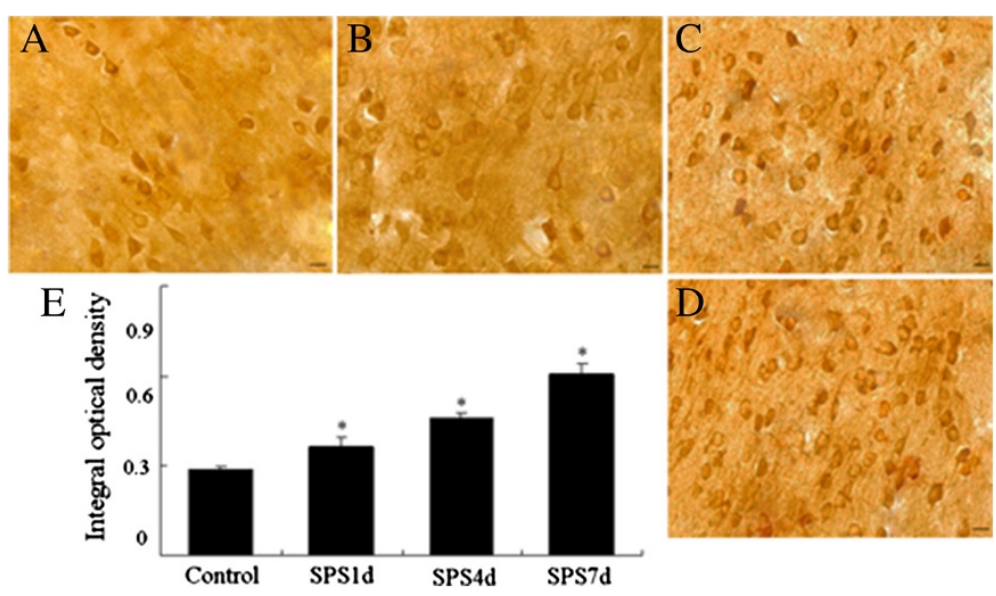

Figure 3 Immunohistochemical observation of GRP78. GRP78-immunoreactivity (ir) in the MPFC of SPS rats in different groups (A-D magnification $\times 400$ ). A: the control group; B: the SPS1d group; C: the SPS4d group; D: the SPS7d group; E: the quantity of GRP78-ir expression (OD). $n=5$ for each group, scale bar $=30$ um, and statistical analysis was carried out by Tukey test. ${ }^{*} \mathrm{P}<0.05$ versus control.

and peaked at 7 days after SPS stimulation (Figure 5B and 5C). These results were consistent with them of immunohistochemical staining analysis, and suggested SPS triggered inductions of GRP78 and ERP57.

\section{SPS induced persistently upregulations in the transcripts levels of GRP78 and ERP57}

Furthermore, we also examined an increase in total transcripts levels of GRP78 and ERP57 in the mPFC by RTPCR. In control rats, very low level of GRP78 and ERP57 mRNA were detected (Figure 6A), however, the mRNA expression of GRP78 and ERP57 both had a persistently significant increase in SPS rats (Figure 6A), expecially at 4 days and 7 days after SPS (Figure 6B and 6C). These results revealed SPS induced persistently upregulations in the transcripts levels of GRP78 and ERP57.

\section{SPS induced cell death through ER stress and activation of caspases}

Just as shown as the Figure 7, brown particles presented in the nucleus under microscopy were apoptosis-positive cells detected by TUNEL staining. The control group showed a small amount of apoptosis-positive cells and has a lighter colour. However, 7 days after exposed to SPS, the amount of apoptosis-positive cells increased obviously and the color of brown particles became deeper, and there was a significant difference in the number of apoptosis-positive cells compared with that of the control group (shown in Figure 7E), which further suggested the existence of the mPFC apoptosis. And to see the changes in cellular agents related to ER stress and apoptosis, then tissue extracted from the $\mathrm{mPFC}$ were detected by RT-PCR, and the results showed that the mRNA level of the executor of ER
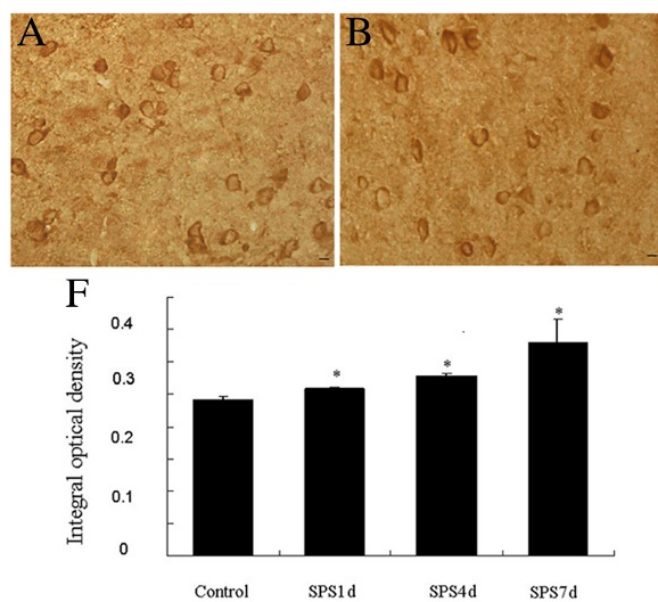
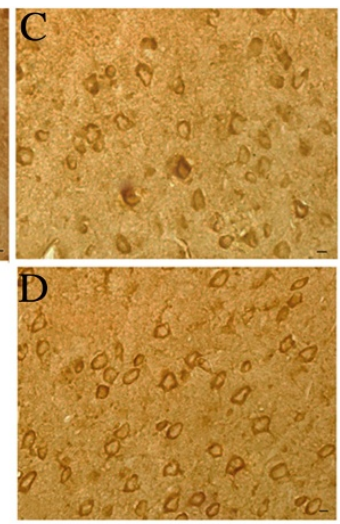

Figure 4 Immunohistochemical observation of ERP57. ERP57-immunoreactivity (ir) in the mPFC of SPS rats in different groups (A-D, magnification $\times 400)$. A: the control group; B: the SPS1d group; C: the SPS4d group; $\mathbf{D}$ : the SPS7d group; E: the quantity of ERP57-ir expression (OD). $n=5$ for each group, scale bar $=30$ um, and statistical analysis was carried out by Tukey test. ${ }^{*} \mathrm{P}<0.05$ versus control. 

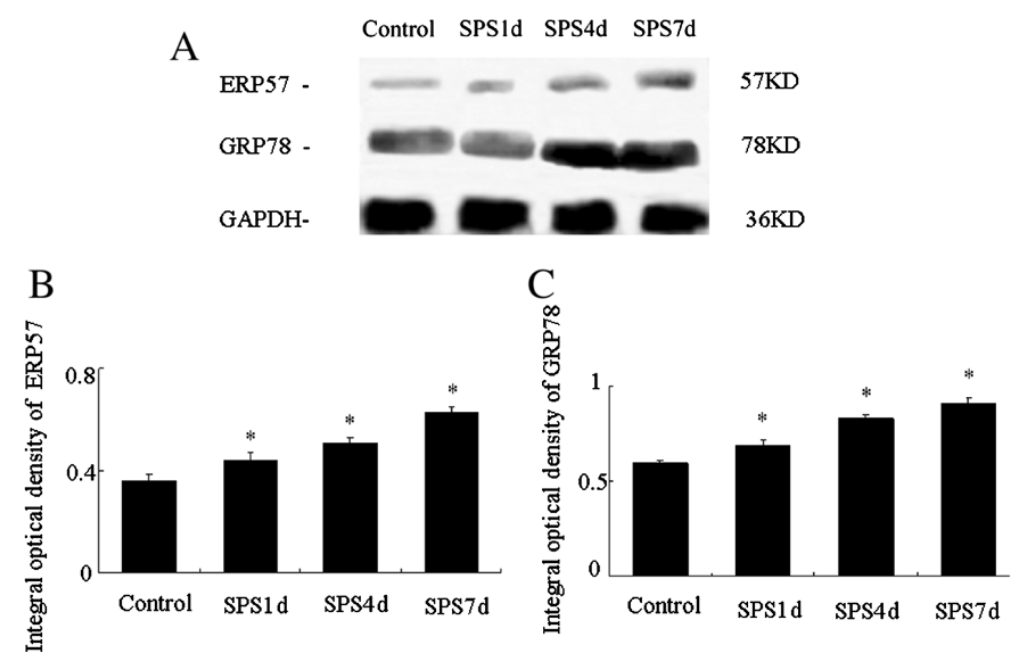

Figure 5 Changes of GRP78 and ERP57 levels in the MPFC of SPS rats detected by Western blotting. Typical Bands by Western blotting were shown in (A), and relative analysis of GRP78 and ERP57 were shown in (B) and (C), respectively. Statistical analysis was carried out by Tukey test. ${ }^{*} \mathrm{P}<0.05$ versus control.

apoptosis, Caspase 12, was persistently increased till 7 days after SPS (Figure 8A and 8B), which suggested Caspase 12 was activated by SPS, revealing signs of ER stress-induced apoptosis. Meanwhile, the mRNA amounts of Caspase 9 was gradually up regulated till 7 days after SPS exposure (shown in Figure 8B) at 7 days after SPS exposure, and the mRNA level of Caspase 3 had no significant difference compared to the control group at the early stage of SPS, however, there was dramatically increase at 7 days after SPS exposure (shown in Figure 8B). The up-regulation of the mRNA level of Caspase 9 and Caspase 3 suggested
Caspase 9 and Caspase 3 were activated after SPS, and all those results indicate that ER stress and caspase activation contribute to SPS and SPS-induced apoptosis.

\section{Discussion}

PTSD is a stress-related mental disorder that can develop in individuals who have been exposed to an event or events that involved the threat of death or serious injury and reacted with intense fear, helplessness or horror [1]. Although enormous progress has been made over the past decade in understanding on the molecular mechanism of
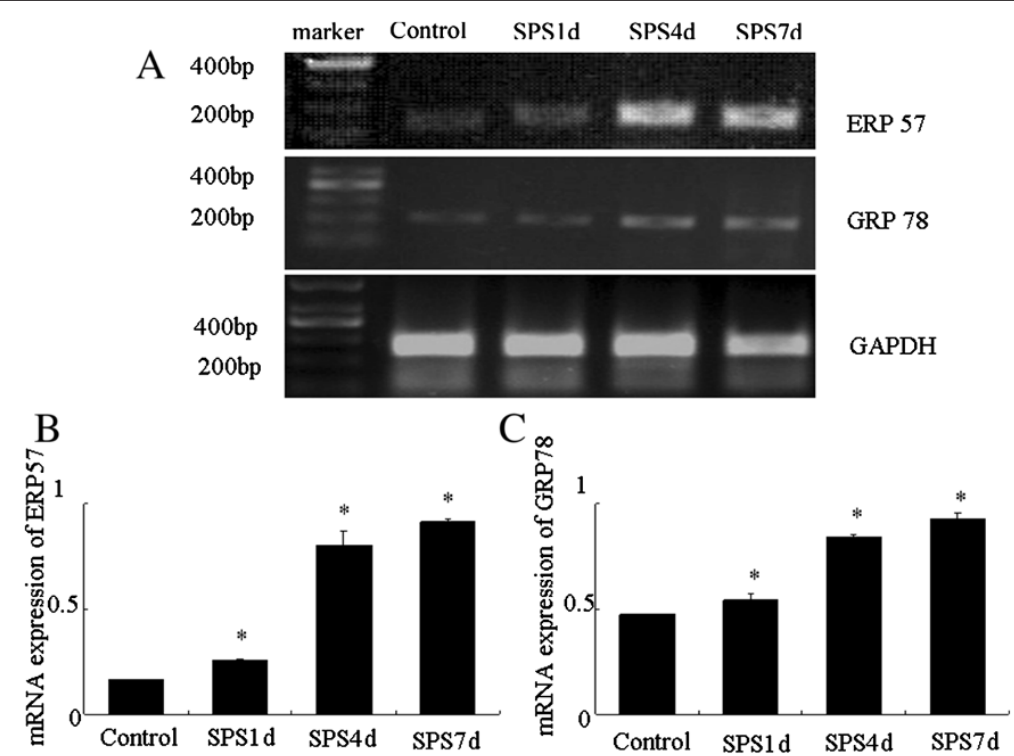

Figure 6 Difference in GRP78 and ERP57 mRNA levels in control rats and SPS rats detected by RT-PCR. Representative gel pattern of CDNA were shown in (A), and relative amount of GRP78 and ERP57 mRNA were shown in (B) and (C), respectively. Statistical analysis was carried out by Tukey test. ${ }^{*} \mathrm{P}<0.05$ versus control. 


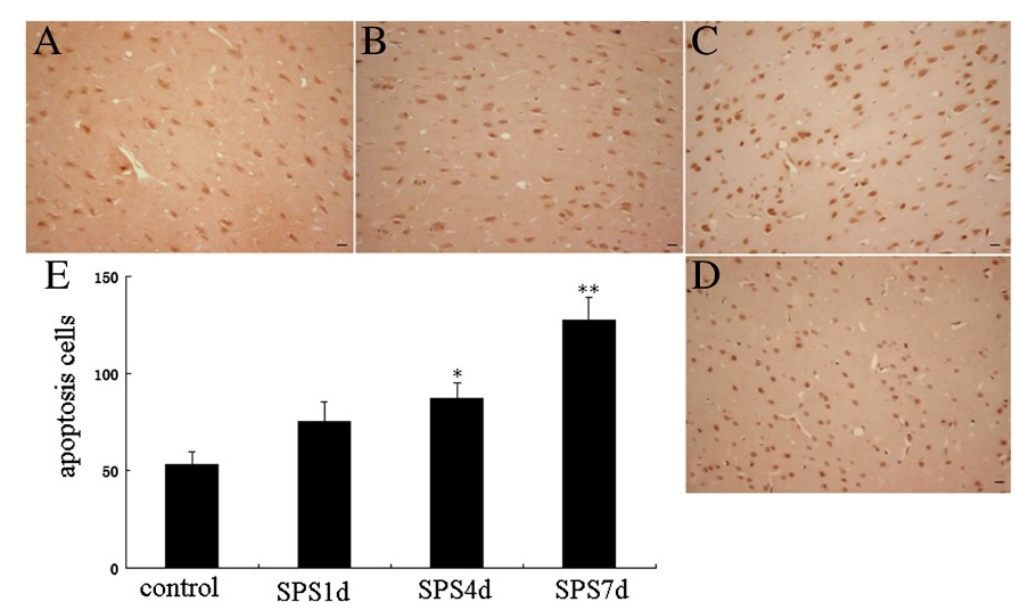

Figure 7 Apoptosis detected by TUNEL assays. The Representative images were shown in (A-D, magnification $\times$ 400), A: the control group; B: the SPS1d group; C: the SPS4d group; D: the SPS7d group; and $\mathbf{E}$ shows quantification of apoptosis cells. Statistical analysis was carried out by Tukey test. ${ }^{*} \mathrm{P}<0.05$ versus control, ${ }^{* *} \mathrm{P}<0.05$ versus control.

PTSD, the exact pathogenesis remains obscured. Several magnetic resonance imaging (MRI) studies have reported decreased frontal cortex volume in PTSD [37-39] and decreased volume in medial prefrontal regions [40-43], some functional neuroimaging studies have typically reported less activation or even deactivation in ventral mPFC regions during traumatic script-driven imagery in PTSD [6-8]; and animal data also have demonstrated the vmPFC is critically involved in the extinction of the acquisition and expression of conditioned fear [44-46], particularly in the recall of extinction after a long delay $[47,48]$. These reports above have suggested that $\mathrm{mPFC}$ has been implicated in the pathogenesis of PTSD, and thus in this paper, we focused on this structure in order to understand further the pathological mechanism of PTSD.

SPS is a model for PSTD employed extensively [49,50], which determined at the International PTSD Scientific Meeting held by Japanese Ministry of Education in 2005. Animal experimental researches verify that rats after SPS exposure have dysfunction in hypothalamic-pituitaryadrena (HPA) axle, changes in ethology, activity habits, memory abilities and environmental adaptability reduces, in conformity with clinical manifestation of human PTSD. And SPS could also mimic the specific neuroendocrinological abnormalities observed in PTSD patients, by conducting in three stages: restraint for $2 \mathrm{~h}$, forced swim for $20 \mathrm{~min}$, and ether anesthesia, which correspond to psychological, physiological, and endocrinological stress, respectively. In current experiment, we set up SPS model and carried out MWM test to confirm whether the model succeeded. From Figure 1A and B, we could observed that the escape latency was prolonged in SPS rats at day 1 through day 6, and when the platform was removed from the pool at day 7 for spatial memory testing, SPS rats had much less time spent in target quadrant compared to the control rats. All these results revealed that SPS model in this study was successfully copied, which had provided guarantee for subsequent studies.

Given in our previous studies, our research teammate Wen et al. [51] have proved that there were abnormal expression of $\mathrm{Ca}^{2+}$-CaM-CaMKII $\alpha$ pathway in the $\mathrm{mPFC}$
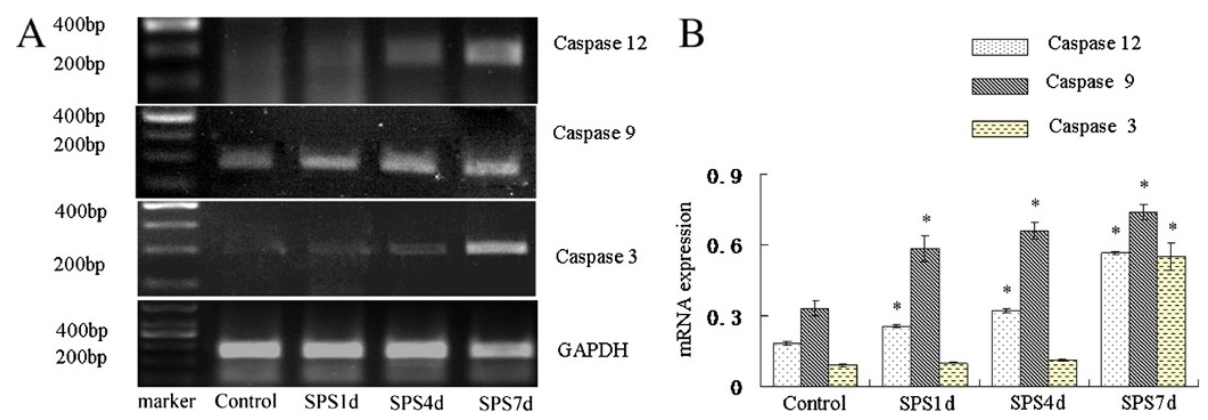

Figure 8 RT-PCR of Caspase 12, Caspase 9 and Caspase 3 in the mPFC of SPS rats. The Caspase 12, Caspase 9 and Caspase 3 mRNA expression (A) and the results from their quantitative analysis (B). Statistical analysis was carried out by Tukey test. ${ }^{*} \mathrm{P}<0.05$ versus control. 
neurons, and dysfunction of cytosolic $\mathrm{Ca} 2+$ concentration was taken as one of inducement of ER stress, we deduced that ER stress would be induced by dysfunction of $\mathrm{Ca}^{2+}-\mathrm{CaM}-\mathrm{CaMKII} \alpha$ pathway in the mPFC neurons. And at the same time, our teammate Yana et al. have found that there were expression changes of bcl-2 and bax in the MPFC neurons of SPS-model rats [10]; Zhao et al. [52] also have examined the apoptosis morphological changes by transmission electron microscopy (TEM) and demonstrated the existence of apoptosis in the mPFC neurons of rats after SPS. As ER stress would induce apoptosis, thus in this paper we hypothesized that ER stress and ER-related apoptosis would be involved in the molecular mechanisms of SPS-induced apoptosis in the mPFC neurons of PTSD-like rats.

And as we all know, ATF6 $\alpha$ is a typical ER stress transducer $[53,54]$, and to elucidate its potential alterations in the mPFC neurons after SPS exposure, firstly we evaluated the levels of ATF $6 \alpha$ by the use of immunofluorescence assay. As shown in Figure 2B-D and 2E, obvious increases of ATF6 $\alpha$ were detected in response to SPS, started at the early stage and persistently increased till 7 days, which indicated that SPS activated ER stress transducer ATF6 $\alpha$. And as at the beginning of ER stress ATF6 $\alpha$ pathway triggers and results in the upregulation of ER-derived chaperones to rescue cells from ER stress $[18,24,25]$, next we detected the expression of a key regulator of ER stress GRP78 by immunohistochemistry, western blotting and RT-PCR. Our results showed that the protein expression of GRP78 increased 1, 4 days, peaked on 7 days after SPS stimulation, and the mRNA expression changes of GRP78 were similar to the trend of its protein changes, which revealed that there was accumulation of GRP78 in the mPFC neurons in response to SPS. The accumulation of GRP78 are beneficial because on one hand, as a chaperone, GRP78 recognizes and binds to the proteins with hydrophobic residues in the unfolded regions to assist with the correct folding of the unfolded proteins [55]; and on the other hand, GRP78 also can form in a large multi-protein complex with a set of ER molecular chaperones, GRP94, PDI, ERp57, and so on, which forms an ER chaperoning network processing the unfolded protein substrates [56].

Given the ATF6 $\alpha$ pathway also can trigger and result in the upregulation of protein-folding enzymes ERP57 $[24,25,29]$, we also observed the protein and mRNA expression of ERP57, and our results showed that there were increased expressions in the protein level and the mRNA level of ERP57. ERP57 is a $58-\mathrm{kDa}$ protein with significant homology to protein disulfide isomerase and has two thioredoxin-like domains and is suspected to function as thiol-dependent oxidoreductase [57]. ERP57 can interact with glycoproteins such as calnexin and calreticulin, playing an important role as a molecular chaperone during glycoprotein biosynthesis and folding [22], and also can promote the formation of intra- or intermolecular disulfide bonds during glycoprotein folding [58-60] to cope with excessive protein folding load and re-establish cellular homeostasis, and it has reported that ERP57 has shown clinical applications to endoplasmic reticulum stress associated diseases and cancer [61], disruption of ERP57 in mouse is lethal. And during ER stress, when the ATF6 $\alpha$ pathway is activated, the active nuclear form of ATF6 $\alpha$ is transported in the nuclear and then induces the upregulation of ERP57 to copy with the ER stress, which just as we saw from our results that the expression of ERP57 was up-regulated in the neurons of the $\mathrm{MPFC}$ in response to SPS, and comprehensive the above results of GRP78, we can draw a conclusion that SPS triggered not only the induction of GRP78, but also the induction of ERP57, which both are the downstream of the ATF6 $\alpha$ pathway and indicators of ER stress, and that is, ATF6 $\alpha$ pathway ER stress was induced in the MPFC neurons in response to SPS.

As when ER stress is prolonged or severe, apoptotic pathways can be activated $[62,63]$, next we evaluated apoptosis using the TUNEL assay and performed RT-PCR analysis of the total transcripts levels of Caspase 12, which is a key signal involved in ER stress-induced apoptosis [28,29], and we observed the number of apoptosis-positive cells increased obviously 7 days after exposed to SPS (shown in Figure 7), and the mRNA of Caspase 12 also was persistently increased till 7 days after SPS, revealing signs of ER stress-induced apoptosis. And furthermore, as the activated Caspase 12 will enter cytoplasm from ER, and gradually activate Caspase 9 and Caspase 3, then we also observed the mRNA expression changes of Caspase 9 and Caspase 3, and found that there were dramatically increase in the mRNA level of them at 7 days after SPS exposure (shown in Figure 8B), which suggested Caspase 9 and Caspase 3 were also activated after SPS. Taken together, we could draw a conclusion that SPS induced cell death through ER stress and activation of caspases, ER stress-induced apoptosis contributed to SPS. However, as the activation of Caspase 3 and 9 also can occur by mitochondrial apoptotic pathway, therefore, it is necessary to identify whether the mitochondrial apoptotic pathway also play key roles in inducing apotosis of the MPFC after SPS, which is one of the limitations in this experiment. And furthermore, it is still required to elucidate the precise mechanism underlying SPS-induced ER stress and ER stressrelated apoptosis.

\section{Conclusion}

In summary, our studies demonstrated that SPS triggered the activation of ATF $6 \alpha$ and the increase of GRP78 and ERP57, and also up regulated the transcripts levels of Caspase 12, Caspase 9 and Caspase 3. Our 
results indicated that SPS induced ATF6 $\alpha$-dependent ER stress and ER stress-related apoptosis in the MPFC neurons, which indicated that the endoplasmic reticulum pathway may be involved in PTSD-induced apoptosis and may provide important information for the pathogenesis and treatment of PTSD.

\section{Abbreviations}

ANOVA: Analysis of variance; con: Control group; DAB: 3,30-diaminobenzidine: ER: Endoplasmic reticulum; GAPDH: Glyceraldehyde-3-phosphate dehydrogenase; GRP78: Glucose-regulated protein 78; IR: Immunoreactivity; OD: Optical density; PFA: Pre-cold paraformaldehyde; PTSD: Post-traumatic stress disorder; PVDF: Polyvinylidene fluoride; RT-PCR: Reverse transcription-polymerase chain reaction; SPS: Single-prolongedstress; UPR: Unfold protein response.

\section{Competing interest}

The authors declare that they have no competing interest.

\section{Authors' contributions}

Conceived and designed the experiments: YS Performed the experiments, analyzed the data and wrote the paper: BY, LW, and BX, Contributed reagents/materials/analysis tools: $\mathrm{FH}$. All authors read and approved the final manuscript.

\section{Acknowledgments}

This work was supported by two grants from the National Natural Science Foundation of China (No. 31200772; No. 81171282) and a research fund from the Doctoral Program of Higher Education of China (No. 20132104110021 ).

\section{Author details}

'PTSD laboratory, Department of Histology and Embryology, Institute of Pathology and Pathophysiology, China Medical University, Shenyang, China. ${ }^{2}$ Department of Neurosurgery, Shengjing Hospital, China Medical University, Shenyang, China. ${ }^{3}$ Institute of pathology and pathophysiology, Department of Histology and Embryology, Basic Medical Sciences College, China Medical University, 92 North 2nd Road, Shenyang 110001, Liaoning Province, P.R. China.

Received: 13 June 2014 Accepted: 3 October 2014

Published online: 21 October 2014

\section{References}

1. Zhu CZ, Situ MJ, Zhang Y, Fang H, Jing LS, Wang D, Yan J, Huang Y: Influence factors of posttraumatic stress disorder (PTSD) and depression symptoms in children and adolescents after Wenchuan earthquake in China. Zhonghua Yu Fang Yi Xue Za Zhi 2011, 45:531-536.

2. Pollice R, Bianchini V, Roncone R, Casacchia M: Psychological distress and post-traumatic stress disorder (PTSD) in young survivors of L'Aquila earthquake. Riv Psichiatr 2012, 47:59-64.

3. American Psychiatric Association: Diagnostic and Statistical Manual of Mental Disorders. 5th edition. Arlington, VA: American Psychiatric Association; 2013.

4. Frick KM, Baxter MG, Markowaska AL, Olton DS, Price DL: Age-related spatial reference and working memory deficits assessed in the water maze. Neurobiolo Aging 1995, 16:149-160.

5. Sherin JE, Nemeroff CB: Post-traumatic stress disorder: the neurobiological impact of psychological trauma. Dialogues Clin Neurosci 2011, 13:263-278.

6. Bremner JD, Narayan M, Staib LH, Southwick SM, McGlashan T, Chamey DS Neural correlates of memories of childhood sexual abuse in women with and without posttraumatic stress disorder. Am J Psychiatry 1999, 156:1787-1795.

7. Shin LM, Orr SP, Carson MA, Rauch SL, Macklin ML, Lasko NB, Peters PM, Metzger L, Dougherty DD, Cannistraro PA, Alpert NM, Fischman AJ, Pitman RK: Regional cerebral blood flow in amygdala and medial prefrontal cortex during traumatic imagery in male and female Vietnam veterans with PTSD. Arch Gen Psychiatry 2004, 6:168-176.

8. Shin LM, McNally RJ, Kosslyn SM, Thompson WL, Rauch SL, Alpert NM, Metzger L, Lasko NB, Orr SP, Pitman RK: Regional cerebral blood flow during script-driven imagery in childhood sexual abuse-related PTSD: a PET investigation. Am J Psychiatry 1999, 156:575-584.
9. Hull AM: Neuroimaging findings in post-traumatic stress disorder Systematic review. Br J Psychiatry 2002, 181:102-110.

10. Li Y, Han F, Yuxiu S: Increased neuronal apoptosis in medial prefrontal cortex is accompanied with changes of $\mathrm{BCl}-2$ and $\mathrm{Bax}$ in a rat model of post-traumatic stress disorder. J Mol Neurosci 2013, 51:127-137.

11. Liberzon I, Krstov M, Young EA: Stress-restress: effects on ACTH and fast feedback. Psychoneuroendocrinology 1997, 22:443-453.

12. Yehuda R: Neuroendocrine aspects of PTSD. Handb Exp Pharmacol 2005, 169:371-403.

13. Boyce M, Yuan J: Cellular response to endoplasmic reticulum stress: matter of life or death. Cell Death Differ 2006, 13:63-373.

14. Kaufman RJ: Orchestrating the unfolded protein response in health and disease. J Clin Invest 2002, 101:1389-1398.

15. Schroder M, Kaufman RJ: ER stress and the unfolded protein response. Mut Res 2005, 569:29-63.

16. Harding HP, Zhang Y, Bertolotti A, Zeng H, Ron D: Perk is essential for translational regulation and cell survival during the unfolded protein response. Mol Cell 2000, 5:897-904.

17. Yoshida H, Matsui T, Yamamoto A, Okada T, Mori K: XBP1 mRNA is induced by ATF6 and spliced by iRE1 in response to ER stress to produce a highly active transcription factor. Cell 2001, 107:881-891.

18. Yoshida H, Okada T, Haze K, Yanagi H, Yura T, Negishi M, Mori K: ATF6 activated by proteolysis directly binds in the presence of NF-Y (CBF) to the cis-acting element responsible for the mammalian unfolded protein response. Mol Cell Biol 2000, 20:6755-6767.

19. Whitesell L, Bagatell R, Falsey R: The stress response: implications for the clinical development of hsp90 inhibitors. Cancer Drug Targets 2003, 3:349-358.

20. Chang YJ, Tai CJ, Kuo LJ, Wei PL, Liang HH, Liu TZ, Wang W, Tai CJ, Ho YS, Wu CH, Huang MT: Glucose-regulated protein 78 (GRP78) mediated the efficacy to curcumin treatment on hepatocellular carcinoma. Ann Surg Oncol 2011, 18:2395-2403.

21. Bertolotti A, Zhang Y, Hendershot LM, Harding HP, Ron D: Dynamic interaction of BiP and ER stress transducers in the unfolded-protein response. Nat Cell Biol 2000, 2:326-332.

22. Jessop CE, Chakravarthi S, Garbi N, Hammerling GJ, Lovell S, Bulleid NJ: ERp57 is essential for efficient folding of glycoproteins sharing common structural domains. EMBO J 2007, 26:28-40.

23. Rao RV, Peel A, Logvinova A, del Rio G, Hermei E, Yokota T, Goldsmith PC, Ellerby LM, Ellerby HM, Bredesen DE: Coupling endoplasmic reticulum stress to the cell death program: role of the ER chaperone GRP78. FEBS Lett 2002, 514:122-128.

24. Hong M, Luo S, Baumeister P, Huang JM, Gogia RK, Li M, Lee AS: Underglycosylation of ATF6 as a novel sensing mechanism for activation of the unfolded protein response. J Biol Chem 2004, 279:11354-11363.

25. Nadanaka S, Okada T, Yoshida H, Mori K: Role of disulfide bridges formed in the luminal domain of ATF6 in sensing endoplasmic reticulum stress. Mol Cell Biol 2007, 27:1027-1043.

26. Tabas I, Ron D: Integrating the mechanisms of apoptosis induced by endoplasmic reticulum stress. Nat Cell Biol 2011, 13:184-190.

27. Bernales S, Papa FR, Walter P: Intracellular signaling by the unfolded protein response. Annu Rev Cell Dev Biol 2006, 22:487-508.

28. Nakagawa T, Zhu H, Morishima N, Li E, Xu J, Yankner BA, Yuan J: Caspase-12 mediates endoplasmic-reticulum-specific apoptosis and cytotoxicity by amyloidbeta. Nature 2000, 6:98-103.

29. Ma Y, Hendershot LM: Delineation of a negative feedback regulatory loop that controls protein translation during endoplasmic reticulum stress. J Biol Chem 2003, 278:34864-34873.

30. Ding J, Han F, Shi Y: Single-prolonged stress induces apoptosis in the amygdala in a rat model of post-traumatic stress disorder. $J$ Psychiatr Res 2010, 44:48-55.

31. Yu J, Liu C, Zhang X, Han J: Acupuncture improved cognitive impairment caused by multi-infarct dementia in rats. Physiol Behav 2005, 86:434-441.

32. Paxinos G, Watson C: The Rat Brain in Stereotaxic Coordinates. San Diego: Academic Press; 1998.

33. Haze $\mathrm{K}$, Yoshida H, Yanagi $\mathrm{H}$, Yura T, Mori K: Mammalian transcription factor ATF6 is synthesized as a transmembrane protein and activated by proteolysis in response to endoplasmic reticulum stress. Mol Biol Cell 1999, 10:3787-3799.

34. Yoshida $H$, Haze $K$, Yanagi $H$, Yura T, Mori K: Identification of the cis-acting endoplasmic reticulum stress response element responsible for 
transcriptional induction of mammalian glucose-regulated proteins Involvement of basic leucine zipper transcription factors. J Biol Chem 1998, 273:33741-33749.

35. Yu Z, Luo H, Fu W, Mattson MP: The endoplasmic reticulum stressresponsive protein GRP78 protects neurons against excitotoxicity and apoptosis: suppression of oxidative stress and stabilization of calcium homeostasis. Exp Neurol 1999, 155:302-314.

36. Werstuck GH, Lentz SR, Dayal S, Hossain GS, Sood SK, Shi YY, Zhou J, Maeda N, Krisans SK, Malinow MR, Austin RC: Homocysteine-induced endoplasmic reticulum stress cause dysregulation of the cholesterol and triglyceride biosynthetic pathways. J Clin Invest 2001, 107:1263-1273.

37. De Bellis M, Keshavan MS, Shifflett H, lyengar S, Beers SR, Hall J, Moritz G: Brain structures in pediatric maltreatment-related post-traumatic stress disorder: a sociodemographically matched study. Biol Psychiatry 2002, 52:1066-1078

38. Carrion V, Weems C, Eliez S, Patwardhan A, Brown W, Ray RD, Reiss AL: Attenuation of frontal asymmetry in pediatric posttraumatic stress disorder. Bio Psychiatry 2001, 50:943-951.

39. Fennema-Notestine C, Stein MB, Kennedy CM, Archibald SL, Jernigan TL: Brain morphometry in female victims of intimate partner violence with and without posttraumatic stress disorder. Biol Psychiatry 2002, 52:1089-1101

40. Rauch SL, Shin LM, Segal E, Pitman RK, Carson MA, McMullin K, Whalen PJ, Makris N: Selectively reduced regional cortical volumes in post-traumatic stress disorder. Neuroreport 2003, 14:913-916.

41. Yamasue H, Kasai K, Iwanami A, Ohtani T, Yamada H, Abe O, Kuroki N, Fukuda R, Tochigi M, Furukawa S, Sadamatsu M, Sasaki T, Aoki S, Ohtomo K, Asukai N, Kato N: Voxel-based analysis of MRI reveals anterior cingulate gray-matter volume reduction in posttraumatic stress disorder due to terrorism. Proc Natl Acad Sci U S A 2003, 100:9039-9043.

42. Woodward SH, Kaloupek DG, Street CC, Martinez C, Schaer M, Eliez S: Decreased anterior cingulate volume in combat-related PTSD. Biol Psychiatry 2006, 59:582-587.

43. Rogers MA, Yamasue $H$, Abe O, Yamada H, Ohtani T, Iwanami A, Aoki S, Kato N, Kasai K: Smaller amygdale volume and reduced anterior cingulated gray matter density associated with history of post-traumatic stress disorder. Psychiatry Res 2009, 174:210-216.

44. Butter CM, Mishkin M, Rosvold HE: Conditioning and extinction of a food-rewarded response after selective ablations of frontal cortex in rhesus monkeys. Exp Neurol 1963, 7:65-75.

45. Morgan MA, LeDoux JE: Differential contribution of dorsal and ventral medial prefrontal cortex to the acquisition and extinction of conditioned fear in rats. Behav Neurosci 1995, 109:681-688.

46. Morgan MA, Romanski LM, LeDoux JE: Extinction of emotional learning: contribution of medial prefrontal cortex. Neurosci Lett 1993, 163:109-113.

47. Lebron K, Milad MR, Quirk GJ: Delayed recall of fear extinction in rats with lesions of ventral medial prefrontal cortex. Learn Mem 2000, 11:544-548.

48. Quirk GJ, Russo GK, Barron JL, Lebron K: The role of ventromedial prefrontal cortex in the recovery of extinguished fear. J Neurosci 2000, 20:6225-6231

49. Khan S, Liberzon I: Topiramate attenuates exaggerated acoustic startle in an animal model of PTSD. Psychopharmacology (Berl) 2004, 172:225-229.

50. Takahashi T, Morinobu S, Iwamoto Y, Yamawaki S: Effect of paroxetine on enhanced contextual fear induced by single prolonged stress in rats. Psychopharmacology (Berl) 2006, 189:165-0173.

51. Wen Y, Bin L, Fang H, Shi Y: Dysfunction of calcium/calmodulin/CaM kinase lla cascades in the medial prefrontal cortex in post-traumatic stress disorder. Mol Med Rep 2012, 6:1140-1144.

52. Zhao D, Han F, Shi Y: Effect of glucose-regulated protein 94 and endoplasmic reticulum modulator caspase-12 in medial prefrontal cortex in a rat model of posttraumatic stress disorder. $J$ Mol Neurosci. In press.

53. Nadanaka S, Yoshida H, Sato R, Mori K: Analysis of ATF6 activation in Site-2 protease-deficient Chinese hamster ovary cells. Cell Struct Funct 2006, 31:109-116.

54. Adachi Y, Yamamoto K, Okada T, Yoshida H, Harada A, Mori K: ATF6 is a transcription factor specializing in the regulation of quality control proteins in the endoplasmic reticulum. Cell Struct Funct 2008, 33:75-89.

55. Flynn GC, Pohl J, Flocco MT, Rothman JE: Peptide-binding specificity of the molecular chaperone BiP. Nature 1991, 353:726-730.

56. Meunier L, Usherwood YK, Chung KT, Hendershot LM: A subset of chaperones and folding enzymes form multiprotein complexes in endoplasmic reticulum to bind nascent proteins. Mol Biol Cell 2002, 13:4456-4469.

57. Khanal RC, Nemere I: The ERp57/GRp58/1,25D3-MARRS receptor: multiple functional roles in diverse cell systems. Curr Med Chem 2007, 14:1087-1093.

58. Ellgaard L, Helenius A: Quality control in the endoplasmic reticulum. Nat Rev Mol Cell Biol 2003, 4:181-191.

59. Kostova Z, Wolf DH: For whom the bell tolls: protein quality control of the endoplasmic reticulum and the ubiquitin-proteasome connection. EMBO J 2003, 22:2309-2317.

60. Schrag JD, Procopio DO, Cygler M, Thomas DY, Bergeron JJ: Lectin control of protein folding and sorting in the secretory pathway. Trends Biochem Sci 2003, 28:49-57.

61. Lee AS: The glucose-regulated proteins: stress induction and clinical applications. Trends in Biochem Sci 2001, 26:504-510

62. Breckenridge DG, Germain M, Mathai JP, Nguyen M, Shore GC: Regulation of apoptosis by endoplasmic reticulum pathways. Oncogene 2003 22:8608-8618.

63. Rutkowski DT, Kaufman RJ: A trip to the ER: coping with stress. Trends Cell Biol 2004, 14:20-28.

doi:10.1186/s12868-014-0115-5

Cite this article as: Yu et al:: Single Prolonged Stress induces ATF6 alpha-dependent Endoplasmic reticulum stress and the apoptotic process in medial Frontal Cortex neurons. BMC Neuroscience 2014 15:115.

\section{Submit your next manuscript to BioMed Central and take full advantage of:}

- Convenient online submission

- Thorough peer review

- No space constraints or color figure charges

- Immediate publication on acceptance

- Inclusion in PubMed, CAS, Scopus and Google Scholar

- Research which is freely available for redistribution
C Biomed Central 